\title{
VIGNETTE
}

\section{What's Under the Cloth?}

\author{
CRAIG DWYER \\ International School of Ulm/Neu-Ulm (Germany)
}

Autumn was everywhere you looked in Tokyo. The subways were crowded with workers in suit jackets. Gone were the short-sleeved shirts and sweaty brows of summer. A pleasant smell of kinmokuse flowers hung in the air. The evenings were crisp, but not cold, and the cicadas had long since gone silent. Trees were shedding their leaves and the wind would pick up the offerings and twist and turn them in the air, leaving not-so neat little piles on the side of road, crowded in the gutters, and drifted against the sides of buildings. Though Tokyo is a city that never sleeps, there were occasional moments of silent clarity, almost as if the city were trying to rid itself of the noise and motion, and just enjoy the cool breeze.

It was the autumn of 2010, and I found myself sitting in a cleared out music classroom at Tokyo International School with about one hundred other teachers. There were drum kits stacked in the corner and we were sitting next to a pile of trumpets. I had made the $600 \mathrm{~km}$ trip south from Aomori, where I lived and worked, to join a workshop with an Australian education consultant. The topic was Teaching and Learning Through Inquiry. We spent two days engaged in deep questions about the purpose of school, what a thinking curriculum should look like, and how to evoke a sense of wonder in our students, not wonder in the sense of amazing, but rather a profound sense of curiosity.

We came back from a wonderful lunch on the second day to find a shroud of red and white tartan cloth sitting on our table. Our facilitator asked us not to touch the cloth, but to wonder what was underneath. Some members of our table got very close and smelled the cloth, but it emitted no odor. Others listened carefully, but it made no sound. We tried hard to see if the white spots on the fabric were translucent enough to allow a ray of light to slip in and reveal a color, or a texture. It did not. In our limited perspective, it appeared to be simply a bump under a piece of fabric.

Next, we were permitted to touch the cloth with the palms of our hands. We could discern shape. We could feel texture. We could tell how hard the item was. These few sensorial indicators gave birth to something at our table. Ideas began to fly. Theories. Conjectures. Somebody grabbed a piece of paper and a pencil (which were placed off to the side beforehand but never mentioned) and started scribbling down our thinking. The more people suggested, the more the image became real. We all felt different things, and the variety of experience pushed us down unexplored paths

Suddenly, an announcement was made that we could now use our fingers. We took turns, slowly turning it over in our hands, feeling, poking and prodding every nook and 
cranny, careful not to disturb the shroud and spoil the drama. I remember feeling a new sense of amazement for these long appendages that I use daily but never considered deeply. The philosophy of my fingers. They are amazing when you stop and consider, when you empty your head and watch them work.

As we felt the mystery object under the shroud, we thought out loud, and slowly a theory began to form. Several theories began to form, each one connected to the other. Some of these theories were connected to the first theories, others were completely new, and still others appeared out of both.

These theories were not born out of our observations of the thing we were inquiring into, but rather they emerged from our questions. As one person asked a question, it sparked another question, which gave birth to a new thought from which new questions would come forth. Our mindful attention to our questions, and our openness to travel down new paths gave us all a sense of purpose. The task required it. There were no predetermined outcomes; instead, curiosity drove us. This thing, this mysterious object, was bringing our minds together which enabled us to wonder out loud.

As we were finally permitted to remove the shroud, we saw the item and we still had no idea what it was. This thing, in plain sight, was still mysterious. Our group experienced a brief moment of silence as we sat, silently contemplating what this thing was. Our initial assumption had been that we would remove the shroud and be faced with familiarity. We were not, yet this did not stop our inquiries. We came up with several theories, and spurred on by a collective sense of amazement, we continued to guess and add new strands to our network of thoughts.

I wish I could explain to you now what this looked like, or what it felt like, or what our theories about it were, but I can't. The truth is, I don't remember. I can't recall a single thing about the object. Not one. She may have told us what it was, but I do not recall. I remember she told us she had picked it up from a yard sale many years ago and had fallen in love with its mysterious qualities. I remember her mentioning how she always gets nervous taking these weird looking items through customs at airports. I remember everything about the activity, the people, the color of the table, the light in the room, the beautiful handwriting on our brainstorming sheet in multi-colored markers. I remember the sense of collective awareness that I was feeling in the moment. I remember how ideas were changed by others. I remember the excitement of my colearners as our minds converged on an idea, and I remember the confusion when we began to question our own theories. But as for the actual object itself, the thing we were inquiring into, it is a blank space in my mind. The content of the theories that ebbed and flowed through our group is gone.

All that is left is what I felt, and I felt that our group was operating at a level that was above what any one of us could attain. As a collective of individuals, we were stronger, more open-minded, more creative, and more intelligent that any individual could have been on their own. We accepted the drama of the situation, we were enticed by the rules, and we embraced the ambiguity of the unknown. We were able to do this by being as individual as possible, by bringing pieces of ourselves to the table, and wandering around our ideas. We played with ideas like toys, teased them apart, and put them back together. In the end, not knowing what the object was by no means experienced by me as a sense of defeat (I cannot speak for my co-learners, so I am switching back to the nominal self). Rather, I felt a profound sense of accomplishment. The goal was not the successful naming of the object, but rather the journey we took together. It was about the thinking and the wonder.

This activity has had a profound experience on my views of teaching, learning, and knowing. Learning is a complex phenomenon, not done in isolation, but collectively, with the world around you. It is a creative process, hard to explain, but easy to feel and experience. Bringing awareness to these feelings, and learning to capture these moments and reflect on them has been the greatest thing that nobody bothered teaching me to do 
until now. Allowing a sense of wonder and awe to take over the self is the most liberating precursor to learning.

\title{
In defense of wandering, and in the name of wonder
}

I could spend some time analyzing this vignette from the perspective of a complex system. I could bring up several frameworks and overviews of conditions for emergence. I could cite studies and authors and similar stories.

But I won't.

The truth is, I don't want to. In part because I have been doing it continually for the last three years, as I have re-lived this moment many times. Partly because it exists as a tiny ocean of perfection in my being, and I don't want to disturb the water. And partly because you, as readers of Complicity: An International Journal of Complexity and Education, were probably analyzing it using the same terms and frames of reference as I would have. In a sense, I would speak that unspoken understanding. Would that make it more exciting for you? Or would the feeling get lost? That is a question we can only answer as individuals.

This much I do want to say; a sense of wonder is not a by-product of learning engagements, but an essential component. We, as educators working with learners, can spend a lifetime studying the conditions of emergence and trying to occasion them, or understanding the principles of complex adaptive systems, or orienting attention to emerging ideas; but a sense of wonder in a learner can allow all of it to spring to life with a dazzlingly simple activity. Wonder is the feeling we get, the emotional reaction to viewing something as new. It expands the space we are in and opens new paths to explore.

It invites us into a space where we are free to wander and to wonder.

\begin{abstract}
About the Author
Craig Dwyer is a grade 5 teacher at the International School of Ulm/Neu-Ulm in Southern Germany. He blogs and shares his thoughts at www.teachingparadox.com and you can reach him at dwyerteacher@gmail.com.
\end{abstract}

(C) Copyright 2013. The author, CRAIG DWYER, assigns to the University of Alberta and other educational and non-profit institutions a non-exclusive license to use this document for personal use and in courses of instruction provided that the article is used in full and this copyright statement is reproduced. The author also grants a non-exclusive license to the University of Alberta to publish this document in full on the World Wide Web, and for the document to be published on mirrors on the World Wide Web. Any other usage is prohibited without the express permission of the author. 